This provisional PDF corresponds to the article as it appeared upon acceptance. A copyedited and fully formatted version will be made available soon. The final version may contain major or minor changes.

\title{
Detection of strong inspiratory efforts from the analysis of central venous pressure swings: a preliminary clinical study
}

Jacopo COLOMBO, Elena SPINELLI, Giacomo GRASSELLI, Antonio 0 [PESENTI, Alessandro PROTTI

Minerva Anestesiologica 2020 Aug 04

DOI: 10.23736/S0375-9393.20.14323-2

Article type: Original Paper

(C) 2020 EDIZIONI MINERVA MEDICA

Supplementary material available online at http://www.minervamedica.it

Article first published online: August 4, 2020

Manuscript accepted: July 20, 2020

Manuscript revised: May 11, 2020

Manuscript received: December 2, 2019

Subscription: Information about subscribing to Minerva Medica journals is online at: http://www.minervamedica.it/en/how-to-order-journals.php

Reprints and permissions: For information about reprints and permissions send an email to: journals.dept@minervamedica.it - journals2.dept@minervamedica.it - journals6.dept@minervamedica.it 
Detection of strong inspiratory efforts from the analysis of central venous pressure swings: a preliminary clinical study

Jacopo COLOMBO ${ }^{1}$, Elena SPINELLI ${ }^{2}$, Giacomo GRASSELLI ${ }^{2,3}$, Antonio M. PESENTI ${ }^{2,3}$, Alessandro PROTTI ${ }^{4}$ *

${ }^{1}$ Department of CardioThoracoVascular Anesthesia and Intensive Care, ASST Grande Ospedale Metropolitano Niguarda, Milan, Italy; ${ }^{2}$ Department of Anesthesia, Critical Care and Emergency, Fondazione IRCCS Ca' Granda, Ospedale Maggiore Policlinico, Milan, Italy; ${ }^{3}$ Department of Pathophysiology and Transplantation, Università degli Studi di Milano, Milan, Italy; ${ }^{4}$ Department of Anesthesia and Intensive Care Units, Humanitas Clinical and Research Center - IRCCS, Rozzano (MI), Italy

* Corresponding author: Alessandro Protti, Department of Anesthesia and Intensive Care Units, Humanitas Clinical and Research Center - IRCCS, via Manzoni 56, 20089 Rozzano (MI), Italy. Email: alessandro.protti@hunimed.eu 


\section{ABSTRACT}

BACKGROUND: Swings of central venous pressure $(\triangle \mathrm{CVP})$ may reflect those of pleural and esophageal ( $\triangle \mathrm{PES})$ pressure and, therefore, the strength of inspiration. Strong inspiratory efforts can produce some harm. Herein we preliminarily assessed the diagnostic accuracy of $\Delta \mathrm{CVP}$ for strong inspiratory efforts in critically-ill subjects breathing spontaneously.

METHODS: We measured $\triangle \mathrm{CVP}$ and $\triangle \mathrm{PES}$ in 48 critically-ill subjects breathing spontaneously with zero end-expiratory pressure (ZEEP) or $10 \mathrm{cmH}_{2} \mathrm{O}$ of continuous positive airway pressure (CPAP). The overall diagnostic accuracy of $\triangle \mathrm{CVP}$ for strong inspiratory efforts (arbitrarily defined as $\triangle \mathrm{PES}>8 \mathrm{mmHg}$ ) was described as the area under the receiver operating characteristic (ROC) curve, with 0.50 indicating random guess. The agreement between $\triangle \mathrm{CVP}$ and $\triangle \mathrm{PES}$ was assessed with the Bland-Altman analysis.

RESULTS: $\triangle$ CVP recognized strong inspiratory efforts with an area under the ROC curve of 0.95 (95\% confidence intervals, 0.85-0.99) with ZEEP and 0.89 (0.76-0.96) with CPAP, both significantly larger than $0.50(\mathrm{p}<0.001)$. With the best cut-off value around $8 \mathrm{mmHg}$, the diagnostic accuracy of $\triangle \mathrm{CVP}$ was 0.92 (0.80-0.98) with ZEEP and 0.94 (0.83-0.99) with CPAP. With ZEEP, the median difference between $\triangle \mathrm{CVP}$ and $\triangle \mathrm{PES}$ (bias) was $-0.2 \mathrm{mmHg}$, and the $95 \%$ limits of agreement (LoA) were -3.9 and $+5.5 \mathrm{mmHg}$. With CPAP, bias was $-0.1 \mathrm{mmHg}$, and 95\%-LoA were -5.8 and $+4.5 \mathrm{mmHg}$. In both cases, $\triangle \mathrm{CVP}$ correlated with $\triangle \mathrm{PES}\left(\mathrm{r}_{\mathrm{s}} 0.81\right.$ and $0.67 ; \mathrm{p}<0.001$ for both).

CONCLUSIONS: In critically-ill subjects breathing spontaneously, $\triangle \mathrm{CVP}$ recognized strong inspiratory efforts with acceptable accuracy. Even so, it sometimes largely differed from $\triangle \mathrm{PES}$.

Keywords: dyspnea; respiratory insufficiency; central venous pressure; physical examination 


\section{Introduction}

Critically-ill subjects often make vigorous inspiratory efforts because of anxiety and increased respiratory drive, respiratory system resistance or elastance. ${ }^{1-3}$ If too strong and numerous, these efforts will produce some harm. Blood flow will be diverted from more vital organs towards respiratory muscles, whole-body oxygen consumption will increase, and diaphragm damage will occur. ${ }^{4-6}$ The resulting large driving transpulmonary pressure and tidal volume will injure the lungs. ${ }^{7-10}$ Right ventricular preload, transmural pulmonary vascular pressure, and left ventricular afterload all will increase; if left ventricular function is poor, pulmonary edema will develop. ${ }^{11,12}$ Clinicians should then recognize and treat these abnormally strong inspiratory efforts. ${ }^{13-15}$

During spontaneous breathing, tidal excursions ("swings") of pleural pressure can be estimated as changes of esophageal pressure $(\triangle \mathrm{PES}) .{ }^{16}$ In healthy volunteers, $\triangle \mathrm{PES}$ is few $\mathrm{cmH}_{2} \mathrm{O}$ during quiet breathing but higher than $10-15 \mathrm{cmH}_{2} \mathrm{O}$ during exercise. ${ }^{17,18}$ During assisted mechanical ventilation, peak pressure of the respiratory muscles (another marker of the strength of inspiration) of 5-10 $\mathrm{cmH}_{2} \mathrm{O}$ has been proposed as a reasonable target. ${ }^{14}$ In a series of subjects undergoing a spontaneous breathing trial, $\triangle \mathrm{PES}$ remained around 8 (95\% confidence intervals $[\mathrm{CI}], 1-12) \mathrm{cmH}_{2} \mathrm{O}$ in those who succeeded but progressively increased to 15 (11-19) $\mathrm{cmH}_{2} \mathrm{O}$ in those who failed. ${ }^{19}$ An inspiratory effort with $\triangle \mathrm{PES}>10 \mathrm{cmH}_{2} \mathrm{O}$ (or $>8 \mathrm{mmHg}$ ) might thus be considered abnormally strong, vigorous, or excessive. Even if esophageal pressure is the reference method for measuring inspiratory efforts, it is not routinely measured.

Critically-ill subjects frequently have an intrathoracic central venous catheter. Due to shared anatomical location, swings of central venous pressure $(\triangle \mathrm{CVP})$ may reflect those of pleural and esophageal pressure. Previous studies have compared $\triangle \mathrm{CVP}$ and $\triangle \mathrm{PES}$ during spontaneous breathing. ${ }^{20-24}$ The agreement (i.e., similarity) was sometimes poor, but the correlation (i.e., relationship) was quite always positive and significant. Because of the above finding, the idea of estimating $\triangle \mathrm{PES}$ from $\triangle \mathrm{CVP}$ has been abandoned.

This study aimed to determine the diagnostic accuracy of $\triangle \mathrm{CVP}$ for strong inspiratory efforts (those with $\triangle \mathrm{PES}>8 \mathrm{mmHg}$ ) in subjects recovering from critical illness and breathing spontaneously, and reassess the agreement and correlation between $\triangle \mathrm{CVP}$ and $\triangle \mathrm{PES}$. We hypothesized that large $\triangle \mathrm{CVP}$ generally predicts vigorous inspiratory efforts, although $\triangle \mathrm{CVP}$ and $\triangle \mathrm{PES}$ may sometimes differ from each other. 


\section{Materials and Methods}

This was a single-center prospective observational study performed in a mixed Intensive Care Unit (ICU). It was approved by the local Ethics Committee (Comitato Etico Milano Area B; approval number 1629). Informed consent was always obtained. The study started on 15/07/2015 and ended on 26/01/2018. As the two members of the research team in charge of patients' recruitment (J.C. and E.S.) were not available in the ICU from $11 / 10 / 2015$ to $8 / 5 / 2017$, no patient was enrolled during that period of time.

Subjects breathing spontaneously or undergoing weaning from non-invasive or invasive mechanical ventilation were included if they met all of the following criteria: (1) they had a central venous catheter in the superior vena cava (as verified with chest X-ray) and an esophageal balloon as part of their care; (2) they could sustain two 20-minute trials of spontaneous breathing with either zero end-expiratory pressure (ZEEP) or continuous positive airway pressure (CPAP) $\left(10 \mathrm{cmH}_{2} \mathrm{O}\right)$ according to their attending physicians (who were critical care specialists); and (3) a member of the research team was available. Enrollment occurred at any time during ICU stay. Patients with arrythmia or receiving extracorporeal membrane oxygenation were excluded.

Subjects who entered the study underwent two 20-minute trials of spontaneous breathing with ZEEP or CPAP in random order, in a semirecumbent position $\left(30-45^{\circ}\right)$. At the end of each trial: (1) we recorded the physiological variables of interest, including respiratory rate, heart rate, mean arterial pressure, $\triangle \mathrm{CVP}$, and $\triangle \mathrm{PES}$. Sedation and anxiety were graded according to the Richmond Agitation-Sedation Scale; ${ }^{25}$ (2) patients described their breathing discomfort using the modified Borg Dyspnea Scale, ${ }^{26}$ and (3) attending physicians categorized inspiratory efforts as "normal" or "strong" and patients as "hypovolemic", "normovolemic" or "hypervolemic" based on clinical examination and vital signs, excluding $\triangle \mathrm{CVP}$ and $\triangle \mathrm{PES}$. Performance of arterial and/or central venous blood gas analyses was encouraged but not mandatory. The trial could be terminated early in case of complications (for example, desaturation or hemodynamic instability).

Central venous and esophageal pressures were recorded at $100 \mathrm{~Hz}$, displayed in $\mathrm{mmHg}$, and analyzed on a standard multiparameter monitor (Xprezzon - Spacelab Healthcare, Snoqualmie, WA, USA). Central venous pressure was measured relative to atmospheric pressure, with a fluidfilled transducer leveled $5 \mathrm{~cm}$ below the sternal angle. Esophageal pressure was measured with a balloon (SmartCath - Avea SmartCath Carefusion, San Diego, CA, USA) placed 30-40 cm from the 
nares with visible cardiac artifacts and inspiratory negative swings. The balloon was inflated with 1.0-1.5 $\mathrm{ml}$ of air and connected to an air-filled transducer leveled as needed to display the whole pressure tracing on the monitor (i.e., if the nadir of the esophageal pressure was too negative, the transducer was lowered). In subjects connected to a ventilator, concordance between $\triangle \mathrm{PES}$ and changes in the airway (and pleural) pressure was verified during inspiratory efforts against an occluded airway (Baydur test). ${ }^{16}$ If discordance was larger than $20 \%(\triangle \mathrm{PES} / \triangle \mathrm{PAW}<80 \%$ or $>120 \%$ ), position and inflation of the esophageal balloon were adjusted. $\triangle \mathrm{CVP}$ and $\triangle \mathrm{PES}$ were measured as maximum inspiratory falls, or negative deflections, from end-expiratory levels (Supplementary Digital Material: Supplementary Digital Figure 1). Five consecutive breaths with no evidence of forced expiration or esophageal spasm were analyzed and averaged.

\section{$\underline{\text { Statistical analysis }}$}

Data are presented as mean \pm standard deviation (SD) or median and interquartile range (IQR). Variables of interest were compared between groups with the Student's $t$-test, the Mann-Whitney rank-sum test, and the Fisher exact test.

Our primary aim was to verify whether $\triangle \mathrm{CVP}$ discriminates between normal $(\triangle \mathrm{PES} \leq 8 \mathrm{mmHg})$ and strong ( $\triangle \mathrm{PES}>8 \mathrm{mmHg}$ ) inspiratory efforts in critically-ill subjects breathing with ZEEP or CPAP with moderate accuracy (i.e., with an area under the ROC curve of 0.80 , significantly larger than $0.50) .{ }^{27}$ Our definition of normal and strong inspiratory efforts was arbitrary; it was based on premises reported above. Of note, in a recent study conducted in patients on helmet non-invasive ventilation, $\triangle \mathrm{PES}$ was 5 (3-6) $\mathrm{cmH}_{2} \mathrm{O}$ in those who succeeded and 11 (7-17) $\mathrm{cmH}_{2} \mathrm{O}$ in those who did not, who finally required endotracheal intubation. ${ }^{28}$

The sample size of the study was planned as follows. Type I error rate was set at 0.05; the type II error rate was set at 0.10 (power 0.90). The allocation rate that is the proportion between subjects with normal or strong inspiratory efforts was unknown. We cautiously estimated it could have ranged between 0.25 and 0.75 . For an allocation rate as low as 0.25 or as high as 0.75 , the required sample size was 48 subjects. For any intermediate allocation rate, the required sample size was smaller than that. We then decided to enroll 48 subjects with ZEEP and 48 subjects with CPAP.

The overall diagnostic accuracy of $\triangle \mathrm{CVP}$ was described as the area under the ROC curve with Clopper-Pearson exact 95\%-CI. The value with the highest sensitivity and specificity (Youden's 
index) was considered the best cut-off point. Sensitivity, specificity, and diagnostic accuracy of $\triangle \mathrm{CVP}$ had this point been used as the diagnostic criterion are reported with Clopper-Pearson exact 95\%-CI.

Our secondary aim was to study the agreement and correlation between $\triangle \mathrm{CVP}$ and $\triangle \mathrm{PES}$. Agreement was assessed with the Bland-Altman analysis and described as the median difference (bias) and $2.5^{\text {th }}$ and $97.5^{\text {th }}$ percentiles (95\%-limits of agreement [LoA]). ${ }^{29}$ We considered a divergence $>20 \%(\triangle \mathrm{CVP} / \triangle \mathrm{PES}<80 \%$ or $>120 \%)$ clinically unacceptable, as in the Baydur test. ${ }^{16}$ Correlation was expressed as Spearman's rank coefficient $\left(\mathrm{r}_{\mathrm{s}}\right)$.

Statistical analyses were run with MedCalc 19.0 (MedCalc Software, Ostend, Belgium) and SigmaPlot 11.0 (Jandel Scientific, San Jose, California). A p-value <0.05 was considered statistically significant. 


\section{Results}

We enrolled 49 subjects in total. Forty-seven completed the two trials of spontaneous breathing with ZEEP and CPAP. One could be safely evaluated with CPAP but not with ZEEP, because of progressive desaturation. We thus ended up with 48 subjects evaluated with CPAP but 47 with ZEEP. One other subject was studied with ZEEP only, to reach the planned sample size in that group.

Thirty-three (67\%) subjects were males and 16 (33\%) females; the mean age was $60 \pm 15$ years. The most common reason for admission to the ICU was acute respiratory failure due to pneumonia (18 [37\%] subjects) or that developed after surgery (15 [31\%] subjects). Only three (6\%) subjects presented with acute heart failure. Other reasons for admission and initial severity of disease are reported in the Supplementary Digital Material (Supplementary Table 1).

The study was performed 5 [1-12] days after ICU admission. The main characteristics of the study population at that time are reported in Table 1. On average, $\triangle \mathrm{PES}$ was 6.7 [4.6-9.8] (range 2.2-20.8) $\mathrm{mmHg}$ during spontaneous breathing with ZEEP and 6.1 [3.8-8.1] (range 2.0-19.2) $\mathrm{mmHg}$ with CPAP. Inspiratory efforts with $\triangle \mathrm{PES}>8 \mathrm{mmHg}$ were noted in $20(42 \%)$ subjects with ZEEP and 12 $(25 \%)$ subjects with CPAP.

In Table 2, we compare respiratory rate, heart rate, mean arterial pressure, results of arterial and central venous blood gas analyses (available for approximately three-quarters of the patients), level of sedation and anxiety (judged by the attending physicians) and breathing discomfort (referred by patients) between subjects with $\triangle \mathrm{PES} \leq 8 \mathrm{mmHg}$ or $>8 \mathrm{mmHg}$, during spontaneous breathing with ZEEP or CPAP. None of these variables consistently and significantly differed between the two groups. Moreover, none of these variables was significantly associated with the actual level of $\triangle$ PES (Supplementary Digital Material: Supplementary Digital Figure 2 and Figure 3). As for the attending physicians, they described as "normal" most of the inspiratory efforts with $\triangle \mathrm{PES}>8$ mmHg: 11 out of 20 (55\%) with ZEEP and 10 out of 12 (83\%) with CPAP (Table 2, Figure 1 and Supplementary Digital Figure 4, in the Supplementary Digital Material).

\section{Diagnostic accuracy of $\triangle \mathrm{CVP}$}

With ZEEP, $\triangle$ CVP discriminated inspiratory efforts with $\triangle \mathrm{PES} \leq 8 \mathrm{mmHg}$ from those with $\triangle \mathrm{PES}$ $>8 \mathrm{mmHg}$ with an area under the ROC curve of $0.95(0.85-0.99)(\mathrm{p}<0.001)$. With a best cut-off 
value of $8.2 \mathrm{mmHg}$, sensitivity was $0.85(0.62-0.97)$, specificity $0.96(0.82-1.00)$ and diagnostic accuracy 0.92 (0.80-0.98) (Figure 3). Positive and negative likelihood ratios were 23.8 (3.4-164.5) and 0.16 (0.05-0.40); positive and negative predictive values 0.94 (0.71-0.99) and 0.90 (0.76-0.96). With CPAP, the area under the ROC curve was $0.89(0.76-0.96)(\mathrm{p}<0.001)$. With a best cut-off value of $8.0 \mathrm{mmHg}$, sensitivity was 0.83 (0.52-0.98), specificity 0.97 (0.86-1.00) and diagnostic accuracy 0.94 (0.83-0.99) (Figure 2). Positive and negative likelihood ratios were 30.0 (4.3-210.7) and 0.17 (0.05-0.61); positive and negative predictive values $0.91(0.59-0.99)$ and $0.95(0.83-0.98)$.

\section{$\underline{\text { Agreement and correlation between } \triangle \mathrm{CVP} \text { and } \triangle \mathrm{PES}}$}

With ZEEP, bias was $-0.2 \mathrm{mmHg}$ and 95\%-LoA were -3.9 and $+5.5 \mathrm{mmHg}$ (Figure 3). Despite being significantly correlated $\left(\mathrm{r}_{\mathrm{s}} 0.81 ; \mathrm{p}<0.001\right), \triangle \mathrm{CVP}$ and $\triangle \mathrm{PES}$ diverged by more than $20 \%$ in 16 (33\%) subjects. With CPAP, bias was $-0.1 \mathrm{mmHg}$ and $95 \%$-LoA were -5.8 and $+4.5 \mathrm{mmHg}$ (Figure 3). Once again, $\triangle \mathrm{CVP}$ and $\triangle \mathrm{PES}$ were significantly correlated $\left(\mathrm{r}_{\mathrm{s}} 0.67 ; \mathrm{p}<0.001\right)$ but differed by more than $20 \%$ in as many as $21(43 \%)$ subjects. At the time of the study, four subjects had signs of hypervolemia and 44 had not. The frequency of divergent readings was $75 \%$ (3 subjects) in the former and 30\% (13 subjects) in the latter, with ZEEP ( $\mathrm{p}=0.101) ; 25 \%$ (1 subject) and 45\% (20 subjects) with CPAP ( $\mathrm{p}=0.629)$.

Additional results are reported in the Supplementary Digital Material (Supplementary Table 2-5). 


\section{Discussion}

In subjects recovering from critical illness and breathing spontaneously, $\triangle \mathrm{CVP}$ discriminated normal ( $\triangle \mathrm{PES} \leq 8 \mathrm{mmHg}$ ) from vigorous $(\triangle \mathrm{PES}>8 \mathrm{mmHg}$ ) inspiratory efforts with moderate accuracy and better than any other recorded variable. With ZEEP or CPAP, the mean area under the ROC curve was 0.95 or 0.89 , and the proportion of correct diagnosis, based on the best cut-off value around $8 \mathrm{mmHg}$ (or $10 \mathrm{cmH}_{2} \mathrm{O}$ ), was 0.92 or 0.94 respectively. Even so, $\Delta \mathrm{CVP}$ was not reliable to estimate the exact value of $\triangle \mathrm{PES}$.

In line with previous studies, ${ }^{20-24}$ we report a poor agreement but a positive and significant correlation between $\triangle \mathrm{CVP}$ and $\triangle \mathrm{PES}$. In other words, even if $\triangle \mathrm{CVP}$ and $\triangle \mathrm{PES}$ were not always the same, smaller or larger $\triangle \mathrm{CVP}$ generally reflected smaller or larger $\triangle \mathrm{PES}$. In order to clarify this issue, let us consider two patients, one with $\triangle \mathrm{CVP} 1 \mathrm{mmHg}$ and $\triangle \mathrm{PES} 6 \mathrm{mmHg}$ and the other one with $\triangle \mathrm{CVP} 19 \mathrm{mmHg}$ and $\triangle \mathrm{PES} 11 \mathrm{mmHg}$. In both cases, there is no concordance between $\triangle \mathrm{CVP}$ and $\triangle \mathrm{PES}$. However, as long as one considers $\triangle \mathrm{CVP}$ and $\triangle \mathrm{PES}$ similarly low or similarly high, based on a common threshold of $8 \mathrm{mmHg}, \Delta \mathrm{CVP}$ will correctly signal a normal effort in the first patient and a vigorous effort in the second patient. Obviously, due to the lack of optimal agreement, $\Delta \mathrm{CVP}$ will be inaccurate in some cases.

A recent audit conducted in 50 Countries has shown that one-third of patients in ICU with acute respiratory distress syndrome have some degree of spontaneous breathing. Even so, esophageal pressure is rarely measured. ${ }^{30}$ Physiological variables cannot be accurately estimated based on clinical judgment alone, especially in critically-ill subjects. If their knowledge is meant to affect the process of care, they should be measured. ${ }^{31,32}$ In this present work, attending physicians regarded as normal most of the inspiratory efforts with $\triangle \mathrm{PES}>8 \mathrm{mmHg}$. Our decision to classify those efforts as vigorous or excessive was based only on physiological and pathological premises as more convincing data, from adequately designed clinical studies, were not available at the time of study design. Therefore, the threshold of $\triangle \mathrm{PES}$ above which inspiratory efforts become injurious may differ from $8 \mathrm{mmHg}$. Moreover, our "black or white" approach, with inspiratory efforts classified as "normal" or "strong", is undoubtedly an oversimplification. The risk of lung injury probably progressively increases when $\triangle \mathrm{PES}$ (and transpulmonary pressure) exceeds a critical, physiological value. A "grey-zone" approach may be more indicated. ${ }^{33}$ Even so, we believe that the lack of a strong association between clinical judgment and $\triangle \mathrm{PES}$ is much more important than suggesting a threshold for harm. Some inspiratory efforts were regarded as normal even if they were associated 
with $\triangle \mathrm{PES}$ as large as 12-15 mmHg or even larger (as shown in Figure 1). A clinical diagnosis of respiratory distress is usually based on the presence of tachypnea, tachycardia, and hypoxia. ${ }^{34,35}$ In our study population, respiratory rate, heart rate, and arterial oxygenation were not associated with the strength of inspiration. This was true for other possible signs of increased work of breathing, such as anxiety and central venous oxygen desaturation. In line with these findings, other authors have noted that respiratory rate and oxygenation do not reflect $\triangle \mathrm{PES}$ in hypoxemic subjects treated in ICU. ${ }^{28}$

$\triangle \mathrm{CVP}$ sometimes largely differed from $\triangle \mathrm{PES}$. Some discrepancy might be attributed to methodological issues. For example, we did not verify the exact position of the tip of the central venous catheter, immediately above the junction between the superior vena cava and the right atrium, with the electrocardiogram-technique, ${ }^{36}$ and we did not remove cardiac artifacts from CVP and PES tracings. ${ }^{37,38}$ We prioritized simplicity over more accurate, but also more complex, off-line analysis. Possible additional explanations include fluid overload or severe heart dysfunction with an exaggerated pressure-raising effect of increased venous return during inspiration; ${ }^{39,40}$ use of a noncalibrated esophageal balloon in subjects disconnected from the ventilator (inaccurate measurement of $\triangle \mathrm{PES}$ ); uneven transmission of pleural pressure into the thorax. ${ }^{10}$ The contribution of some of these factors was investigated as reported in the Supplementary Digital Material (Supplementary Table 2 and Figure 4). A large divergence between $\triangle \mathrm{CVP}$ and $\triangle \mathrm{PES}$ was not associated with higher end-expiratory CVP, a clinical diagnosis of hypervolemia, or the use of a non-calibrated esophageal balloon. Other variables that were not recorded probably had a role.

Some of the limitations of this study deserve a final comment. Our study population usually had an initial diagnosis other than heart failure and, by the time of enrollment, had grossly normal hemodynamics with no clear evidence of hypervolemia. In a non-compliant heart, the transmission of pleural pressure to the cardiac cavities can be blunted, and even small changes in volume can produce large changes in pressure: the agreement between $\triangle \mathrm{CVP}$ and $\triangle \mathrm{PES}$ will be particularly poor. ${ }^{39,40}$ But even there, large $\triangle \mathrm{CVP}$ will signal large (or even larger) falls in intra-thoracic pressure. Second, we did not study patients with early and severe acute respiratory distress syndrome, who frequently suffer from right heart failure (a relevant issue for reasons described above) and for whom strong inspiratory efforts are a major concern. ${ }^{9}$ It is our opinion that in these patients, spontaneous breathing should be avoided unless the strength of inspiration can be measured with an esophageal balloon. Third, we did not compare $\Delta \mathrm{CVP}$ with other markers of 
respiratory effort, such as the electrical activity or the thickening fraction of the diaphragm. ${ }^{41} \mathrm{We}$ simply aimed to verify whether $\triangle \mathrm{CVP}$ can be of any help to the attending physician. $\triangle \mathrm{CVP}$ can be readily measured in all subjects with an intrathoracic central venous catheter, with no need for additional competencies. By measuring it, one may easily estimate the strength of inspiration in critically-ill patients, including those undergoing non-invasive ventilation or with a contraindication to the positioning of an esophageal balloon (such as those with facial trauma or after esophageal surgery). 


\section{Conclusions}

In this study population, $\triangle \mathrm{CVP}$ discriminated inspiratory efforts with $\triangle \mathrm{PES} \leq 8 \mathrm{mmHg}$ from those with $\triangle$ PES $>8 \mathrm{mmHg}$ with at least moderate accuracy and better than any other recorded variable. Even so, $\triangle$ CVP did not usually reflect the exact value of $\triangle \mathrm{PES}$. 


\section{WHAT IS KNOWN}

- Clinicians should recognize and treat vigorous and potentially harmful inspiratory efforts that are commonly made by critically-ill patients.

- Even if swings in esophageal pressure ( $\triangle \mathrm{PES}$ ) accurately reflect the strength of inspiration, they are not routinely measured.

\section{WHAT IS NEW}

- In critically-ill subjects breathing spontaneously, $\triangle \mathrm{PES}$ cannot be estimated based on other physiological variables, including respiratory rate, heart rate, and hypoxia.

- Clinicians commonly regard as "normal" the inspiratory efforts associated with abnormally large $\triangle \mathrm{PES}$.

- Swing in central venous pressure $(\triangle \mathrm{CVP})$ can help clinicians discriminate between inspiratory efforts associated with smaller or larger $\triangle \mathrm{PES}$. 


\section{References}

1) Kallet RH, Hemphill JC $3^{\text {rd }}$, Dicker RA, Alonso JA, Campbell AR, Mackersie RC, et al. The spontaneous breathing pattern and work of breathing of patients with acute respiratory distress syndrome and acute lung injury. Respir Care 2007;52:989-995

2) Carteaux G, Millán-Guilarte T, De Prost N, Razazi K, Abid S, Thille AW, et al. Failure of noninvasive ventilation for de novo acute hypoxemic respiratory failure: role of tidal volume. Crit Care Med 2016;44:282-290

3) Crotti S, Bottino N, Ruggeri GM, Spinelli E, Tubiolo D, Lissoni A, et al. Spontaneous breathing during extracorporeal membrane oxygenation in acute respiratory failure. Anesthesiology 2017;126:678-687

4) Viires N, Sillye G, Aubier M, Rassidakis A, Roussos C. Regional blood flow distribution in dog during induced hypotension and low cardiac output. Spontaneous breathing versus artificial ventilation. J Clin Invest 1983;72:935-947

5) Manthous CA, Hall JB, Kushner R, Schmidt GA, Russo G, Wood LD. The effect of mechanical ventilation on oxygen consumption in critically-ill patients. Am J Respir Crit Care Med $1995 ; 151: 210-214$

6) Goligher EC, Brochard LJ, Reid WD, Fan E, Saarela O, Slutsky AS, et al. Diaphragmatic myotrauma: a mediator of prolonged ventilation and poor patient outcomes in acute respiratory failure. Lancet Respir Med 2019;7:90-98

7) Mascheroni D, Kolobow T, Fumagalli R, Moretti MP, Chen V, Buckhold D. Acute respiratory failure following pharmacologically induced hyperventilation: an experimental animal study. Intensive Care Med 1988;15:8-14

8) West JB, Mathieu-Costello O, Jones JH, Birks EK, Logemann RB, Pascoe JR, et al. Stress failure of pulmonary capillaries in racehorses with exercise-induced pulmonary hemorrhage. $\mathbf{J}$ Appl Physiol (1985) 1993;75:1097-1109

9) Brochard L, Slutsky A, Pesenti A. Mechanical ventilation to minimize progression of lung injury in acute respiratory failure. Am J Respir Crit Care Med 2017;195:438-442 
10) Yoshida $T$, Fujino $Y$, Amato MB, Kavanagh BP. Fifty Years of Research in ARDS. Spontaneous breathing during mechanical ventilation. Risks, mechanisms, and management. Am J Respir Crit Care Med 2017;195:985-992

11) Buda AJ, Pinsky MR, Ingels NB Jr, Daughters GT 2 ${ }^{\text {nd }}$, Stinson EB, Alderman EL. Effect of intrathoracic pressure on left ventricular performance. N Engl J Med 1979;301:453-459

12) Lemaire F, Teboul JL, Cinotti L, Giotto G, Abrouk F, Steg G, et al. Acute left ventricular dysfunction during unsuccessful weaning from mechanical ventilation. Anesthesiology 1988;69:171-179

13) Papazian L, Forel JM, Gacouin A, Penot-Ragon C, Perrin G, Loundou A, et al; ACURASYS Study Investigators. Neuromuscular blockers in early acute respiratory distress syndrome. N Engl J Med 2010;363:1107-1116

14) Carteaux G, Mancebo J, Mercat A, Dellamonica J, Richard JC, Aguirre-Bermeo H, et al. Bedside adjustment of proportional assist ventilation to target a predefined range of respiratory effort. Crit Care Med 2013;41:2125-2132

15) Doorduin J, Nollet JL, Roesthuis LH, van Hees HW, Brochard LJ, Sinderby CA, et al. Partial neuromuscular blockade during partial ventilatory support in sedated patients with high tidal volumes. Am J Respir Crit Care Med 2017;195:1033-1042

16) Mauri T, Yoshida T, Bellani G, Goligher EC, Carteaux G, Rittayamai N, et al; PLeUral pressure working Group (PLUG-Acute Respiratory Failure section of the European Society of Intensive Care Medicine). Esophageal and transpulmonary pressure in the clinical setting: meaning, usefulness and perspectives. Intensive Care Med 2016;42:1360-1373

17) Niknam J, Chandra A, Adams AB, Nahum A, Ravenscraft SA, Marini JJ. Effect of a nasogastric tube on esophageal pressure measurement in normal adults. Chest 1994;106:137-141

18) Thomas AM, Turner RE, Tenholder MF. Esophageal pressure measurements in cardiopulmonary exercise testing. Chest 1997;112:829-832 
19) Jubran A, Grant BJ, Laghi F, Parthasarathy S, Tobin MJ. Weaning prediction: esophageal pressure monitoring complements readiness testing. Am J Respir Crit Care Med 2005; 171:1252-1259

20) Hedstrand U, Jakobson S, Nylund U, Sterner H. The concordance of respiratory fluctuations in oesophageal and central venous pressures. Ups J Med Sci 1976;81:49-53

21) Flemale A, Gillard C, Dierckx JP. Comparison of central venous, oesophageal and mouth occlusion pressure with water-filled catheters for estimating pleural pressure changes in healthy adults. Eur Respir J 1988;1:51-57

22) Chieveley-Williams S, Dinner L, Puddicombe A, Field D, Lovell AT, Goldstone JC. Central venous and bladder pressure reflect transdiaphragmatic pressure during pressure support ventilation. Chest 2002;121:533-538

23) Bellemare P, Goldberg P, Magder SA. Variations in pulmonary artery occlusion pressure to estimate changes in pleural pressure. Intensive Care Med 2007;33:2004-2008

24) Verscheure S, Massion PB, Gottfried S, Goldberg P, Samy L, Damas P, et al. Measurement of pleural pressure swings with a fluid-filled esophageal catheter vs. pulmonary artery occlusion pressure. J Crit Care 2017;37:65-71

25) Ely EW, Truman B, Shintani A, Thomason JW, Wheeler AP, Gordon S, et al. Monitoring sedation status over time in ICU patients: reliability and validity of the Richmond AgitationSedation Scale (RASS). JAMA 2003;289:2983-2991

26) Dorman S, Byrne A, Edwards A. Which measurement scales should we use to measure breathlessness in palliative care? A systematic review. Palliat Med 2007;21:177-191

27) Obuchowski NA, Lieber ML, Wians FH Jr. ROC curves in clinical chemistry: uses, misuses, and possible solutions. Clin Chem 2004;50:1118-1125

28) Grieco DL, Menga LS, Raggi V, Bongiovanni F, Anzellotti GM, Tanzarella ES, et al. Physiological comparison of high-flow nasal cannula and helmet non-invasive ventilation in acute hypoxemic respiratory failure. Am J Respir Crit Care Med 2019 Nov 5 [Epub ahead of print] 
29) Bland JM, Altman DG. Statistical methods for assessing agreement between two methods of clinical measurement. Lancet 1986;1:307-310

30) Bellani G, Laffey JG, Pham T, Fan E, Brochard L, Esteban A, et al; LUNG SAFE Investigators; ESICM Trials Group. Epidemiology, patterns of care, and mortality for patients with acute respiratory distress syndrome in intensive care units in 50 countries. JAMA 2016;315:788-800

31) Eisenberg PR, Jaffe AS, Schuster DP. Clinical evaluation compared to pulmonary artery catheterization in the hemodynamic assessment of critically-ill patients. Crit Care Med $1984 ; 12: 549-553$

32) Hiemstra B, Koster G, Wiersema R, Hummel YM, van der Harst P, Snieder H, et al; SICS Study Group. The diagnostic accuracy of clinical examination for estimating cardiac index in critically-ill patients: the Simple Intensive Care Studies-I. Intensive Care Med 2019;45:190-200

33) Coste J, Pouchot J. A grey zone for quantitative diagnostic and screening tests. Int J Epidemiol 2003;32:304-313

34) Decavèle M, Similowski T, Demoule A. Detection and management of dyspnea in mechanically ventilated patients. Curr Opin Crit Care 2019;25:86-94

35) Tulaimat A, Trick WE. DiapHRaGM: A mnemonic to describe the work of breathing in patients with respiratory failure. PLoS One 2017;12:e0179641

36) Pittiruti M, La Greca A, Scoppettuolo G. The electrocardiographic method for positioning the tip of central venous catheters. J Vasc Access. 2011;12:280-291

37) Addabbo T, Cataldo G, Cevenini G, Fort A, Franchi F, Moretti R, et al. A measurement system to estimate the pleural pressure from the CVP for respiratory system monitoring. IEEE Transactions on instrumentation and measurement 2019;68:2469-2478

38) He X, Sun XM, Chen GQ, Yang YL, Shi ZH, Xu M, et al. Use of cardiac cycle locating to minimize the influence of cardiac artifacts on esophageal pressure measurement during dynamic occlusion test. Respir Care 2018;63:169-176 
39) Nakhjavan FK, Palmer WH, McGregor M. Influence of respiration on venous return in pulmonary emphysema. Circulation 1966;33:8-16

40) Magder S, Lagonidis D, Erice F. The use of respiratory variations in right atrial pressure to predict the cardiac output response to PEEP. J Crit Care 2001;16:108-114

41) Bellani G, Pesenti A. Assessing effort and work of breathing. Curr Opin Crit Care 2014;20:352358 


\section{NOTES}

Conflicts of interest. The authors certify that there is no conflict of interest with any financial organization regarding the material discussed in the manuscript.

Authors' contributions. Jacopo Colombo conceived and designed the study, collected data and wrote the manuscript. Elena Spinelli collected data and wrote the manuscript. Giacomo Grasselli enrolled participants and wrote the manuscript. Antonio Pesenti contributed to the design and the implementation of the project and wrote the manuscript. Alessandro Protti conceived and designed the study, performed the analysis, and wrote the manuscript. All authors read and approved this final version of the manuscript.

Congresses. Preliminary results were presented at the $30^{\text {th }}$ SMART (Smart Meeting Anesthesia Resuscitation inTensive care) held in Milan in May, $8^{\text {th }}-10^{\text {th }} 2019$. 
Table 1. Main characteristics of the study population at study entry.

\begin{tabular}{|c|c|}
\hline Airway & \\
\hline - Endotracheal tube, $\mathrm{n} /$ total & $7 / 49$ \\
\hline - Tracheal cannula, $\mathrm{n}$ & $16 / 49$ \\
\hline - Natural, n & $26 / 49$ \\
\hline \multicolumn{2}{|l|}{ Ventilation } \\
\hline - Assisted invasive ventilation, $\mathrm{n}$ & $15 / 49$ \\
\hline - Non-invasive ventilation, $\mathrm{n}$ & $19 / 49$ \\
\hline - Spontaneous breathing, $\mathrm{n}$ & $15 / 49$ \\
\hline $\mathrm{FiO}_{2}, \%$ & $40[30-50]$ \\
\hline Arterial $\mathrm{pH}$ & $7.43 \pm 0.05$ \\
\hline Arterial $\mathrm{CO}_{2}$ tension, $\mathrm{mmHg}$ & $41 \pm 5$ \\
\hline Arterial $\mathrm{O}_{2}$ tension, $\mathrm{mmHg}$ & $91 \pm 24$ \\
\hline Arterial $\mathrm{O}_{2}$ saturation, $\%$ & $95 \pm 2$ \\
\hline $\mathrm{PaO}_{2}: \mathrm{FiO}_{2}(\mathrm{mmHg})$ & $233 \pm 97$ \\
\hline Heart rate, bpm & $86 \pm 15$ \\
\hline Mean arterial pressure, $\mathrm{mmHg}$ & $86 \pm 13$ \\
\hline Central venous pressure, $\mathrm{mmHg}$ & $8 \pm 4$ \\
\hline Central venous $\mathrm{O}_{2}$ saturation, $\%$ & $68 \pm 7$ \\
\hline Lactate, $\mathrm{mmol} / \mathrm{l}$ & $1.1[0.7-1.7]$ \\
\hline Urinary output, $\mathrm{ml} / \mathrm{h}$ & $75[57-102]$ \\
\hline On vasopressor(s), n & $1 / 49$ \\
\hline On continuous renal replacement therapy, $\mathrm{n}$ & $5 / 49$ \\
\hline \multicolumn{2}{|l|}{ Clinical evaluation } \\
\hline - Hypovolemic, $\mathrm{n}$ & $9 / 49$ \\
\hline - $\quad$ Normovolemic, $\mathrm{n}$ & $36 / 49$ \\
\hline - Hypervolemic, $\mathrm{n}$ & $4 / 49$ \\
\hline
\end{tabular}

These are the main characteristics of the 49 subjects included in this study, at the time of their enrollment. $\mathrm{FiO}_{2}$ : fraction of inspiratory oxygen; $\mathrm{PaO}_{2}$ : arterial oxygen tension. Arterial blood gas analyses were not available for seven subjects; central venous $\mathrm{O}_{2}$ saturation was not available for six subjects; arterial or central venous lactate was not available for three subjects; urinary output was not available for four subjects (those on continuous renal replacement therapy). Observed ICUmortality was $8 \%$ (4 deaths). 
Table 2. Comparison between subjects making inspiratory efforts with $\triangle \mathrm{PES} \leq 8 \mathrm{mmHg}$ or $>8 \mathrm{mmHg}$ during spontaneous breathing with ZEEP or with CPAP.

\begin{tabular}{|c|c|c|c|c|c|c|}
\hline & \multicolumn{2}{|c|}{ Spontaneus breathing with ZEEP } & \multirow[b]{2}{*}{$\mathrm{p}$} & \multicolumn{2}{|c|}{ Spontaneous breathing with CPAP } & \multirow[b]{2}{*}{$\mathrm{p}$} \\
\hline & $\Delta \mathrm{PES} \leq 8 \mathrm{mmHg}$ & $\Delta \mathrm{PES}>8 \mathrm{mmHg}$ & & $\Delta \mathrm{PES} \leq 8 \mathrm{mmHg}$ & $\Delta \mathrm{PES}>8 \mathrm{mmHg}$ & \\
\hline $\mathrm{n}$ & 28 & 20 & & 36 & 12 & \\
\hline$\Delta \mathrm{PES}, \mathrm{mmHg}$ & $4.9[3.2-6.0]$ & $11.4[9.0-13.7]$ & NA & $4.8[3.5-6.5]$ & $10.1[9.8-15.0]$ & NA \\
\hline Respiratory rate, $\mathrm{bpm}$ & $22[17-28]$ & $23[19-28]$ & 0.515 & $20[18-26]$ & 19 [14-24] & 0.141 \\
\hline Heart rate, bpm & $85 \pm 13$ & $90 \pm 14$ & 0.195 & $86 \pm 14$ & $87 \pm 15$ & 0.740 \\
\hline Mean arterial pressure, $\mathrm{mmHg}$ & $84 \pm 12$ & $87 \pm 12$ & 0.389 & $89 \pm 14$ & $83 \pm 11$ & 0.212 \\
\hline Arterial $\mathrm{pH}$ & $7.45[7.43-7.47]$ & $7.42[7.38-7.46]$ & 0.120 & $7.43[7.41-7.46]$ & $7.43[7.36-7.47]$ & 0.278 \\
\hline Arterial $\mathrm{CO}_{2}$ tension, $\mathrm{mmHg}$ & $40 \pm 5$ & $39 \pm 7$ & 0.382 & $40 \pm 6$ & $42 \pm 6$ & 0.308 \\
\hline Arterial $\mathrm{O}_{2}$ tension, $\mathrm{mmHg}$ & 78 [66-95] & 85 [68-143] & 0.161 & $103[87-134]$ & $93[67-115]$ & 0.151 \\
\hline Arterial $\mathrm{O}_{2}$ saturation, $\%$ & $96[91-98]$ & $96[93-99]$ & 0.496 & 97 [96-99] & $96[93-98]$ & 0.091 \\
\hline Central venous $\mathrm{O}_{2}$ saturation, $\%$ & $67 \pm 7$ & $70 \pm 7$ & 0.236 & $68 \pm 6$ & $67 \pm 8$ & 0.591 \\
\hline Blood lactate, $\mathrm{mmol} / \mathrm{l}$ & $1.6[0.9-2.0]$ & $1.0[0.8-1.7]$ & 0.289 & $1.5[0.8-1.8]$ & $1.1[1.0-1.2]$ & 0.152 \\
\hline$\Delta \mathrm{CVP}, \mathrm{mmHg}$ & $5.5[4.1-6.5]$ & $10.5[9.1-12.7]$ & $<0.001$ & $4.9[4.2-6.2]$ & $9.8[8.3-13.2]$ & $<0.001$ \\
\hline Richmond Agitation-Sedation Scale & $0[0-0]$ & $0[0-0]$ & 0.425 & $0[0-0]$ & $0[-1-0]$ & 0.658 \\
\hline Modified Borg Dyspnea Scale & $1[0-3]$ & $2[0-2]$ & 0.682 & $0[0-1]$ & $0[0-3]$ & 0.460 \\
\hline \multicolumn{7}{|l|}{ Clinical evaluation } \\
\hline - Normal effort, $\mathrm{n}$ & 23 & 11 & \multirow{2}{*}{0.057} & 32 & 10 & \multirow{2}{*}{0.631} \\
\hline - $\quad$ Strong effort, $\mathrm{n}$ & 5 & 9 & & 4 & 2 & \\
\hline
\end{tabular}

Herein we compare subjects with normal (swing of esophageal pressure $[\Delta \mathrm{PES}] \leq 8 \mathrm{mmHg}$ ) or strong $(\Delta \mathrm{PES}]>8 \mathrm{mmHg}$ ) inspiratory efforts during spontaneous breathing with zero end-expiratory pressure (ZEEP) or continuous positive airway pressure $(\mathrm{CPAP})\left(10 \mathrm{cmH} \mathrm{H}_{2} \mathrm{O}\right) . \Delta \mathrm{CVP}$ : swing of central venous pressure. The Richmond Agitation-Sedation Scale is a 10-point scale to describe individual sedation and anxiety where -5 denotes "unarousable", 0 denotes a calm and alert state, and +4 indicates "combative". ${ }^{26}$ The modified Borg Dyspnea Scale is a 10-point scale to describe individual breathing discomfort where 0 means "none", and 10 means "maximal". ${ }^{27}$ With ZEEP, arterial blood gas analysis was available for 35 
subjects; arterial or central venous lactate for 41 subjects; arterial $\mathrm{O}_{2}$ saturation for 37 subjects; central venous $\mathrm{O}_{2}$ saturation for 35 subjects; and the modified Borg dyspnea scale for 45 subjects. With CPAP, arterial blood gas analysis was available for 37 subjects; arterial or central venous lactate for 41 subjects; arterial $\mathrm{O}_{2}$ saturation for 38 subjects; central venous $\mathrm{O}_{2}$ saturation for 36 subjects; and the modified Borg dyspnea scale for 45 subjects. 
Figure 1. Relationship between the strength of inspiration as assessed by the attending physicians and actual $\triangle$ PES.

The attending physicians were asked to categorize the inspiratory efforts made by 48 critically-ill subjects breathing spontaneously with zero end-expiratory pressure (ZEEP) or continuous positive $\left(10 \mathrm{cmH}_{2} \mathrm{O}\right)$ airway pressure (CPAP) as "normal" or "strong", based on their clinical assessment. They were not aware of the corresponding esophageal pressure ( $\triangle \mathrm{PES})$ and central venous pressure ( $\triangle \mathrm{CVP}$ ) swings. We report the $\triangle \mathrm{PES}$ associated with those inspiratory efforts categorized as normal or strong (one dot per subject), with ZEEP or CPAP. With ZEEP, the inspiratory efforts categorized as normal were associated with a $\triangle \mathrm{PES}$ of 5.9 [4.3-8.9] $\mathrm{mmHg}$; those categorized as strong were associated with a $\triangle \mathrm{PES}$ of 10.2 [6.0-15.5] $\mathrm{mmHg}$ ( $\mathrm{p}=0.005$ for comparison with normal ones). With CPAP, the inspiratory efforts categorized as normal were associated with a $\triangle \mathrm{PES}$ of 6.1 [3.9-8.0] $\mathrm{mmHg}$; those categorized as strong were associated with a $\triangle \mathrm{PES}$ of 6.0 [3.2-12.6] $\mathrm{mmHg}$ $(\mathrm{p}=0.913)$.

Figure 2. Diagnostic accuracy of $\triangle \mathrm{CVP}$ for strong inspiratory efforts.

We describe the overall diagnostic accuracy of swings of central venous pressure $(\Delta C V P)$ for inspiratory efforts with $\triangle \mathrm{PES} \leq 8 \mathrm{mmHg}$ or $>8 \mathrm{mmHg}$ during spontaneous breathing with zero endexpiratory pressure (ZEEP) (panel A) or with continuous positive $\left(10 \mathrm{cmH}_{2} \mathrm{O}\right)$ airway pressure (CPAP) (panel B). An area under the ROC curve (AUROC) of 1.0 indicates a perfect test (sensitivity and specificity both equal to 1.0), while a value of 0.5 indicates no diagnostic capability (random guess).

Figure 3. Agreement between $\triangle \mathrm{CVP}$ and $\triangle \mathrm{PES}$ during spontaneous breathing.

We describe the agreement between swings of central venous pressure ( $\triangle \mathrm{CVP}$ ) and esophageal pressure $(\triangle \mathrm{PES})$ during spontaneous breathing with zero end-expiratory pressure (ZEEP) or with continuous positive $\left(10 \mathrm{cmH}_{2} \mathrm{O}\right)$ airway pressure (CPAP). In panel $\mathrm{A}$ and $\mathrm{C}$ we report the BlandAltman plot referred to spontaneous breathing with ZEEP (panel A) or CPAP (panel C). Solid line indicates bias that is the median difference between $\triangle \mathrm{CVP}$ and $\triangle \mathrm{PES}$; dotted lines indicate $95 \%$ limits of agreement. In panel $\mathrm{B}$ and $\mathrm{D}$ we describe the association between $\triangle \mathrm{CVP}$ and $\triangle \mathrm{PES}$ during 
spontaneous breathing with ZEEP (panel B) or CPAP (panel D). $r_{s}$ : Spearman's rank correlation coefficient. 
With ZEEP

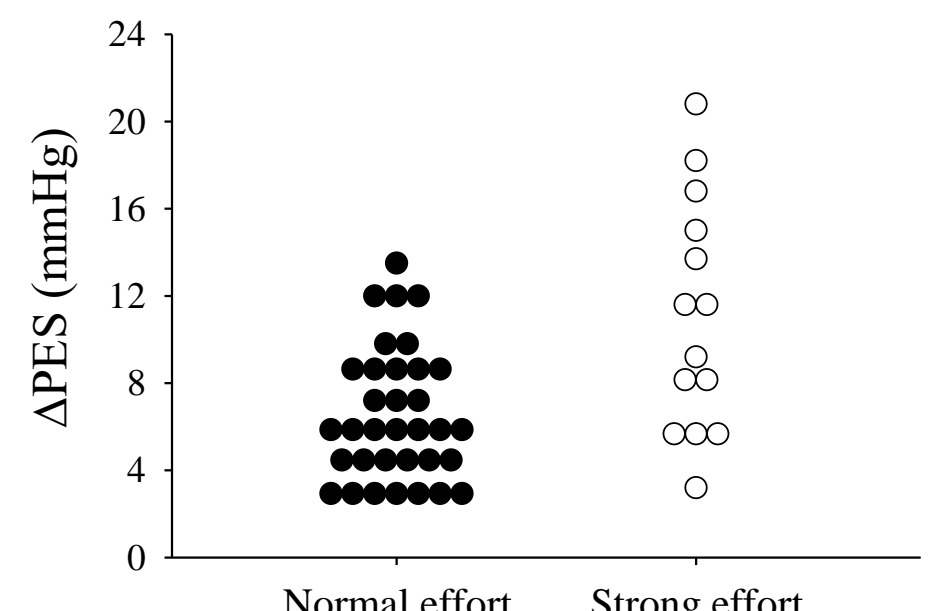

Clinical assessment
With CPAP

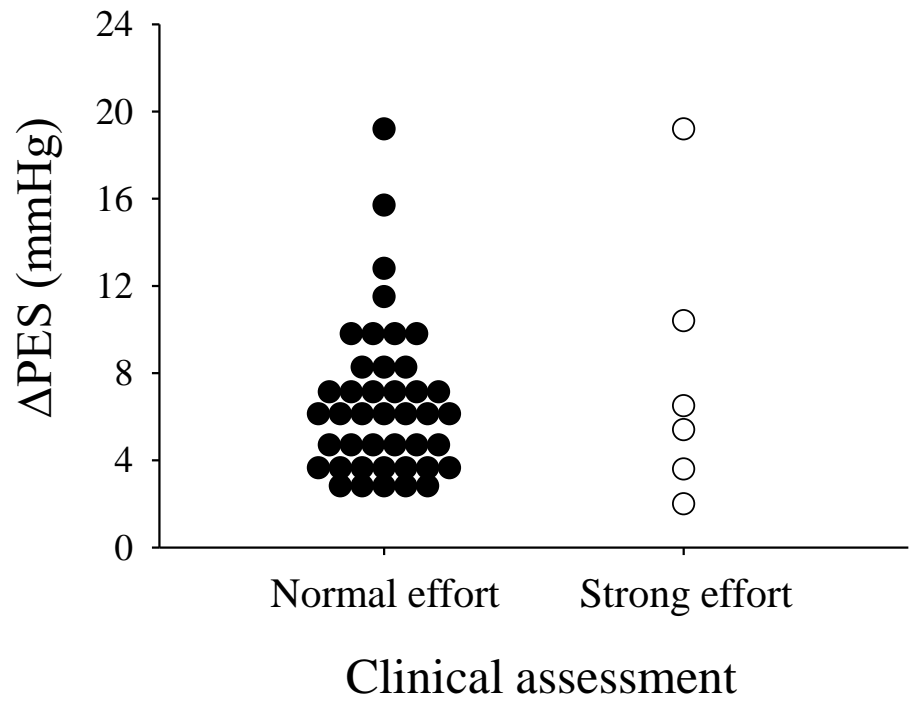

B

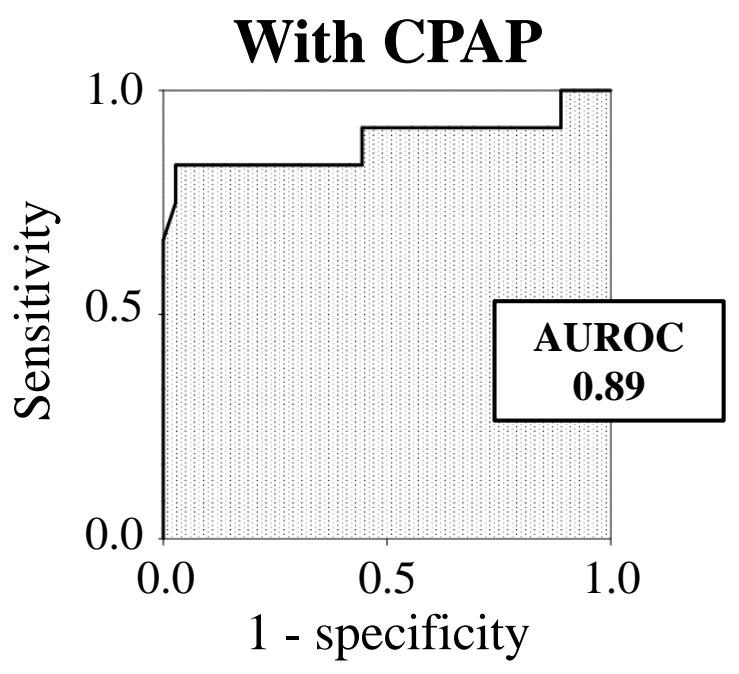

Figure 2 


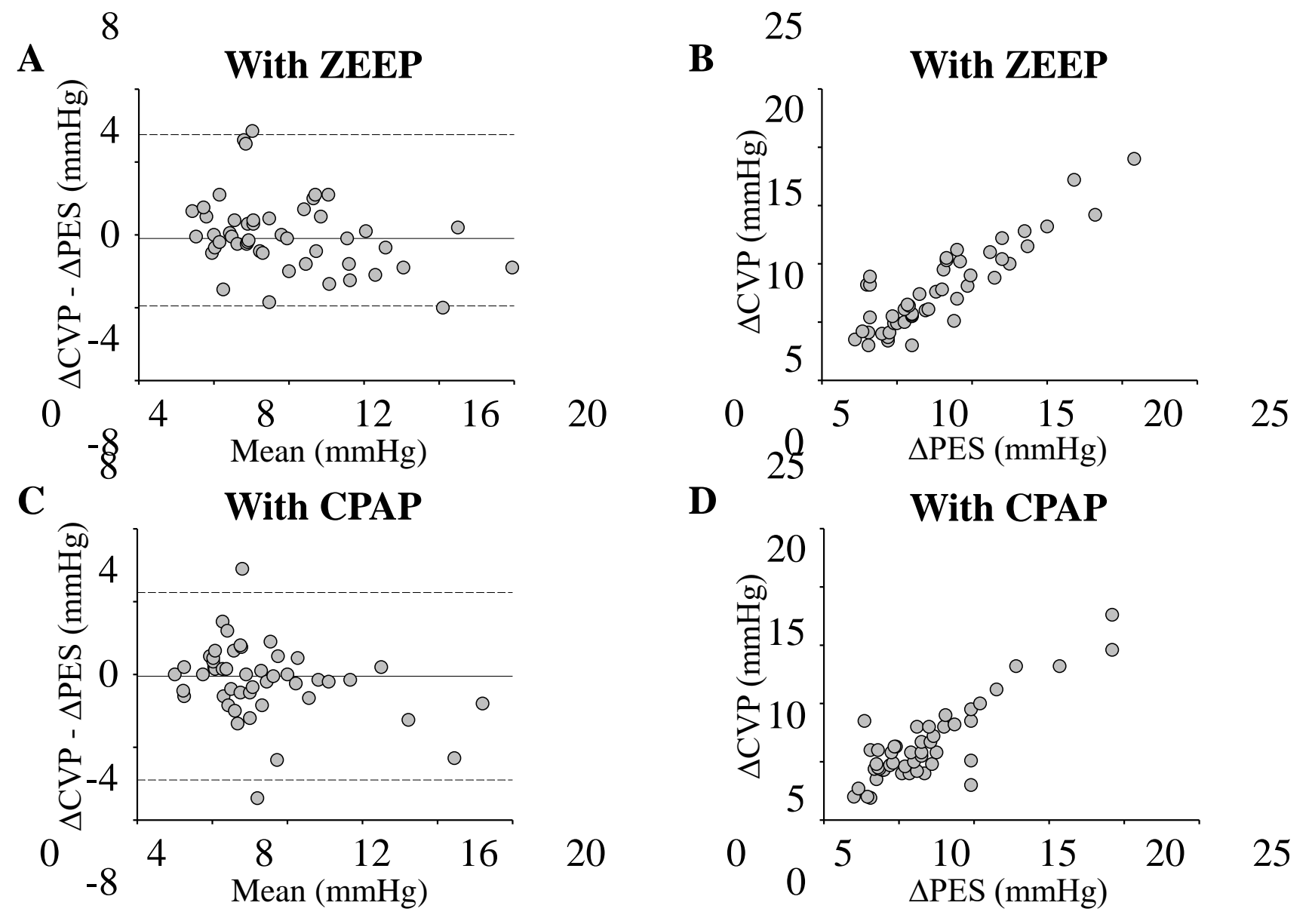

Figure 3 


\section{Supplementary Digital Material}

Download supplementary material file: Minerva Anestesiol-14323 Supplementary Digital Material1_V2_2020-05-07.doc 